\title{
Dificultades del amor erótico en los lazos de inclusión
}

\author{
Maria Alves de Toledo BRUNS ${ }^{1}$
}

Parto de la idea de que el amor erótico es un fenómeno instigador, audaz, temido, enigmático, misterioso y muy complejo, experimentado por los todos los seres humanos indistintamente de su condición cultural y física. Esta condición me permite clasificar el amor erótico como un fenómeno colectivo y transgeneracional, de la misma forma que todos nosotros experimentamos el nacimiento, la vejez, la enfermedad y la muerte.

$\mathrm{Su}$ inicio se dio en el proceso de la evolución de las especies, a través del dominio del instinto/impulso sexual reproductor por el hombre y la mujer. Esto lo transformó en una representación, una ceremonia, mediada en el y por el conjunto de censuras, prácticas, rituales, prohibiciones, mitos y tabúes, lo que nos separa de los demás animales

El amor erótico, al ser una creación del hombre y la mujer, es considerado cultura debido a sus funciones en la sociedad (organización de grupos familiares,

1 Docente e investigadora del Programa de Posgrado en Psicología. Especialista en Sexualidad. USP - Universidad de San Pablo. Facultad de Filosofía Ciencias y Letras. Ribeirão Preto - SP - Brasil. 14040-900. Líder del Grupo de Investigación Sexualidadevida - USP/CNPq. Docente e investigadora del Programa de Posgrado em Educacion Sexual. UNESP - Universidad del Estado de Estado de San Pablo. Faculdad de Ciências y Letras. Araraquara - SP - Brasil. 14800-901 - toledobruns@ uol.com.br 
laborales, de entretenimiento etc.) Incontables reglas, valores morales y sociales, interdictos e permisiones han sido y son creadas por las instituciones a lo largo del tiempo con el objetivo de controlar e de reprimir la expresión de la sexualidad en acordó con el género. El hombre con derecho a una práctica sexual libre y activa y la mujer sumisa al hombre no tenía derecho al placer sexual.

Según Del Priori (2006, nuestra traducción)

Impuso una dicotomía sexual, en la que el hombre fue activo y la mujer pasiva. El deseo sexual se constituye en un derecho exclusivo del hombre, encajar a las esposas, la sumisión y la virtud. El esfuerzo de la formación de los afectos, del amor y la sexualidad, especialmente a feminina, puesto a punto con los objetivos del Estado y de la Iglesia, para que la relación entre los sexos, más cerca del ideal de la sociedad católica, evitando las infracciones que pudieran perturbar.

Este modelo ha ido cambiando con el paso del tiempo debido al carácter ambiguo y transgresor del erotismo: es una represión y un permiso, una exaltación y una perversión (PAZ, 2001).

Desde la perspectiva de Bataille (2004, p.146), "el erotismo es una transgresión a la regla de las prohibiciones: es una actividad humana."

De este modo, "[...] la esencia del erotismo está en la asociación complicada entre el placer y la prohibición. Humanamente, la prohibición nunca se presenta sin el placer, y tampoco el placer se presenta sin el sufrimiento de la prohibición." (BATAILLE, 2004, p.169). Y como tal se transforma al paso que las prohibiciones cambian a lo largo del tiempo.

Con un carácter transgresor, el erotismo es una creación de hombres y mujeres en la búsqueda de la realización psicológica. Gobernado por la lógica inconsciente del principio del placer que choca con el principio de los deberes, el erotismo es una transfiguración, invento y creatividad de cada individuo.

El protagonista del acto erótico es el sexo, más precisamente los sexos. El plural se hace obligatorio porque, con la inclusión de los llamados placeres solitarios, el deseo sexual siempre crea una pareja imaginaria... o muchas. En todos los encuentros eróticos hay uno o dos personajes invisibles que están siempre activos: la imaginación y el deseo. (PAZ, 2001, p.16-20).

Bruns (2011, p.70) expresa que "[...] el cuerpo es el hábitat del erotismo, la fuerza transgresora que triunfa sobre las prohibiciones, valores, prejuicios, estigmas y tabúes de cada sociedad." Bajo el signo de la transgresión, las diversidades sexuales, a lo largo de los siglos, se han revelado como rasgos particulares de masculinidades y feminidades que constituyen estilos transitorios de orientaciones afectivo-sexuales. 
A partir de esta perspectiva transgresora, temida, misteriosa, enigmática y esencialmente inagotable, me propongo en este texto a provocar una reflexión adecuada acerca de las ideas culturales de patriarcado presentes en las dificultades que los individuos considerados normales y los individuos con alguna discapacidad enfrentan al experimentar el amor erótico. Me baso en Paz (2001); Amatuzzi (2009); Bataille (2004); Giddens (1993); Násio (1997); y Dalgalarrondo (2008), entre otros autores cuyos trabajos han llevado a la comprensión de las sutilezas del amor erótico.

Desde esta perspectiva temporal reflexiva, la trayectoria de la SEXUALIDADE humana está marcada por acontecimientos inesperados y dolorosos, que van desde accidentes hasta los más variados síndromes psiquiátricos que, según Dalgalarrondo (2008), comprometen mucho la calidad de las relaciones intrafamiliares y extrafamiliares.

Es común que los individuos considerados normales sean sorprendidos por la disfunción de un órgano, causada por un factor orgánico, glandular, fisiológico o hereditario o por una disfunción sexual de origen psíquica, que se manifiesta en la angustia vivida por un individuo que no soporta el sufrimiento expreso en la trama formada por los rasgos de su deseo, que no le permite experimentar el placer sexual.

Para lo psicoanalista contemporáneo Násio (1997, p.20-21), el sufrimiento representa una "[...] perturbación global psíquica y corporal, ya sea un dolor corporal provocado o una lesión de los tejidos, o un dolor psíquico provocado por la ruptura repentina del lazo íntimo con la persona amada, el dolor que se forma en cuestiones de instantes."

Por ejemplo, la disfunción eréctil, aún en la época del éxito de mercadotecnia de la pastilla milagrosa - el sildenafil - popularmente conocida como Viagra, sigue presente en la vida de algunos hombres de manera discreta.

En la opinión de Grassi (2004, p.28), "[...] fue precisamente la llegada del sildenafil y el éxito del medicamento para el tratamiento de la disfunción eréctil que nos enseñó el fracaso de este individuo, sus fallas y su imposibilidad de vivir sin el síntoma, porque establece a sí mismo como existente, deseador, enfermo.”

Este fracaso se presenta en el individuo inconsciente que expone el pathos, la pasión, su sufrimiento psíquico - su enfermedad real. Acompañe el sufrimiento expreso en el relato de Benedito (nombre ficticio), paciente de 28 ańos, uno de los participantes de la investigación realizada por Grassi (2004, p.24):

Me siento sin salida. Ando de un lado a otro, pero no voy a ninguna parte y siempre vuelvo al mismo punto. No puedo elegir un camino y seguirlo. Siento un hueco enorme, es como si nada existiera. A veces pienso que si me muriera sería mejor. Hago planes, pienso en el futuro, pero en seguida viene el 
recuerdo del problema de erección, esa tristeza, y todo acaba. Desisto de todo y mi cabeza es como un globo que gira, pienso en problemas todo el tiempo.

Podemos observar que el sufrimiento de Benedito se expresa como una perturbación psíquica-corporal intensa e inestable que se manifiesta en todo el cuerpo. Este descontento indica la existencia de un sufrimiento psíquico que se origina en el proceso de asumir su identidad masculina, la cual, según Pereira (2004, p.12-13) "[...] se manifiesta en la crisis de identidad masculina a lo largo de los siglos XX y XXI, originada en el proceso de disminución de la referencia paterna y en las transformaciones históricas, sociales, económicas y culturales."

Es importante aclarar que estas transformaciones se desarrollaron de las y por las fisuras en los patrones de sentidos: familia, escuela, religión, ciencia, Estado, economía, medios y otros que, de modo dialéctico, debilitaron silenciosamente las sólidas bases fálicas construidas tradicionalmente en el y por el ethos del patriarcado que legitimaba el lugar y el estilo de virilidad y potencia sexual.

Los efectos de estas transformaciones han amenazado este estilo de organización simbólica basada en las referencias firmes al Padre Simbólico, de modo que revela su propia vulnerabilidad en las construcciones de ilusiones de identidades masculinas.

Para Pereira (2004, p.13), “[...] la desesperación humana se presenta en su forma más radical, y la proliferación de sufrimientos como la depresión, el pánico, el aburrimiento, las toxicomanías y el trastorno 'límite' de la personalidad o borderline tienen relación con el momento de la historia del occidente." Esta realidad, combinada con nuevas subjetividades, exige nuevas organizaciones simbólicas para calmar el anhelo por el hiperdesempeño sexual, para armonizar el hombre contemporáneo con los nuevos estilos de masculinidad.

Una investigación de Santos (2006) con hombres con cáncer de próstata en el rango de edad de 50 a 80 años descubrió que la manifestación del cáncer acentúa la diminución de la respuesta sexual, la presencia de la disfunción eréctil y la pérdida de la identidad sexual.

El significado y el sentido del cuerpo erotizado enfermo revelan el encarcelamiento del hombre, rehén de este estado de ser, a su modelo de virilidad. Cuando la virilidad falla, la desesperación y la humillación hacen con que el hombre confronte este ideal de masculinidad, y el sufrimiento se instala. Sin embargo, algunos hombres vuelven a la paz a través de la afectividad de la esposa-madre - la cuidadora - que lo llena de carińo y afecto, de modo que experimentan el proceso de (des)erotización. Este sufrimiento genera una autoacogida, auto-comprensión de la transformación del cuerpo enfermo, y la pareja se adueña de sí misma en una forma de existir que alcanza el punto más íntimo uno del otro. 
En este encuentro, ambos se confortan y se acercan a una relación auténtica. Es común que los diálogos se den sobre la (no) permanencia de la propia existencia enfocada en la división de bienes y de encuentros con amigos y seres queridos.

Los inconformes se desesperan por la pérdida de la virilidad - para ellos, el sentido de la vida se pierde entre tonos de gris y la convivencia con la familia ocurre de forma dolorosa.

Al confrontarse con la (des)erotización en conexión con la posibilidad de la finitud, los recuerdos son agrios y amargos y se apoyan en una postura agresiva hacia los cuidadores. Rebeldes y descontentos, ellos parecen expresar que la vida es un engaño.

El confronto con la muerte se da en el hecho de que estos hombres no son dueños de la propia existencia - son seres mortales. Como todos los demás. Esta realidad, para algunos, se presenta de modo trágico al darse cuenta de la reducción de la dimensión del futuro, el nuevo existir como seres faltantes. Falta sentido para llenar este vacío donde no hay sentido. Como afirma Brum (2012), en general, una vida que tiene sentido es aquella en que los sentidos se construyen para perderse más adelante, y se reconstruyen una y otra vez. Al final, es el vacío lo que nos hace crear una vida humana - y no morir antes de la muerte.

En este (des)compás, crear espacios de diálogos y reflexiones con el objetivo de generar la desconstrucción del encarcelamiento del hombre con cáncer de próstata al ideal hegemónico de la virilidad puede estimular y ampliar la visión de otros hombres y de los profesionales de la salud en el sentido de considerar las propias condiciones de orfandad de este hombre para enfrentar la disfunción eréctil, así como para reorientarse hacia la concientización de la temporalidad del cuerpo que envejece, se enferma, se deserotiza y muere.

Para Dichtchekenian (1988, p.105), “[...] la muerte se presenta en la doble cara del antiguo (como la finitud que cargamos) y del nuevo, que nos sorprende, alejándonos de nosotros mismos o de la seguridad narcisista." En este proceso, nos confrontamos con la finitud de la temporalidad de la existencia.

De esta forma, el proceso de enfermarse y envejecer, sea o no un individuo discapacitado, se presenta en las transformaciones del cuerpo en sus aspectos físicos, hormonales, cognitivos, eróticos-sexuales, emocionales, psíquicos y espirituales, entre otros, al mismo tiempo que nos hace ver con asombro la (no) permanencia de nuestra propia existencia. El sufrimiento nos saca de la inestimable ligereza de nuestra fragilidad de persona saludable y nos impone limitaciones, lesiones del cuerpo - hábitat de circunstancias trágicas e insoportables.

Otra fuente aclaradora de las dificultades de experimentar el amor erótico es la investigación que hizo Barbosa (2003) con 10 hombres con lesión medular 
adquirida. Su deseo era comprender el mundo-vida de estos hombres antes y después de las secuelas de la lesión, además de comprender los significados y sentidos que atribuyen a la vida.

Antes de la lesión medular mi relación sexual era activa, ¿̇erdad? [...] a veces íbamos a una fiesta y a veces 'hacíamos el amor' con dos, tres, cuatro, hasta cinco chicas. Era un fin de semana sagrado... [risas]. [...] Antes de la lesión uno no tenía siquiera que tocar a la chica, uno la miraba y el pene ya estaba erecto, y uno ya quería acercarse y ligar [...]. [...] Entonces mi vida sexual antes del balazo era excelente, muy activa, de verdad [...]. [Colaborador 6, 24 años, cortador de telas] (BARBOSA, 2003, p.89).

Bueno, cuando yo tenía... cuando yo caminaba normalmente, mi sexualidad era una sexualidad normal, ¿̇verdad? Yo era activo, demasiado activo [...]. [...] no eran relaciones de caricias, no eran relaciones de toques... Lo hacíamos, se acabó, se acabó, había la penetración, no había toques, caricias, no había esa cosa rica, ¿sabes? [Colaborador 8, 29 ańos, psicólogo] (BARBOSA, 2003, p.89).

Para mí el sexo siempre ha sido algo para hacerse diario, todos los días yo tenía una relación sexual. Una vez en la ciudad X yo salí con cuatro mujeres distintas, yo salía con varias chicas, novias de mis amigos y esposas de mis amigos [...]. [Colaborador 10, 44 años, vendedor de libros] (BARBOSA, 2003, p.90).

Estos relatos de los colaboradores de Barbosa (2003) muestran la énfasis que ellos ponen en el desempeńo sexual con foco en la cantidad de relaciones sexuales. Para estos hombres, ser viril es no rechazar ninguna posibilidad de satisfacer sus incontrolables deseos. Estos deseos se enfocan únicamente en su propia satisfacción, la mujer era sólo un objeto de consumo desechado después del uso. La manera impersonal y la ausencia de vínculos caracterizan la forma de ser de estos hombres.

Al fin, los hombres en general fueron educados para tener placer y no para intercambiar placer. Este modelo de hombre desconectado de la vida afectiva, a pesar de estar en profunda modificación, representa el ethos de patriarcado que todavía está presente en el estilo del hombre contemporáneo. Este es el ideal de virilidad de este ethos y, en su antítesis, el de feminidad.

En las palabras de Marrega e Bruns (2009, p.83),

[...] la identidad femenina y masculina eran comprendidas como si fueran la expresión de una esencia biológica inmutable. Ser mujer significaba poseer el instinto innato para tener hijos y, por lo tanto, un don 'natura' para la educación y las actividades tiernas de cuidado y afecto, volviéndose 
indispensable al cuidado de los hijos y del esposo en el ambiente privado da la familia burguesa.

Los relatos de estos individuos revelan el encarcelamiento al sexo que involucra los órganos genitales como confirmación de la virilidad. Ejecutan el modelo de masculinidad compulsiva. Según Giddens (1993, p.131), "[...] el sentido masculino de auto-identidad, por lo tanto, se basa en circunstancias que asocian una orientación hacia la auto-suficiencia con una desventaja emocional potencialmente mutiladora."

Como consecuencia, el falo se transforma en el propio pene como si tuviera vida propia. Para el autor, en este ámbito "[...] la sexualidad masculina se somete, por un lado, a la dominación sexual agresiva, incluso con uso de violencia, y por otro lado, a constantes ansiedades relativas a la potencia (que probablemente se manifiestan con más frecuencia en relaciones con alguna duración, en las cuales el desempeño no se separa de las experiencias emocionales de varios tipos." (GIDDENS,1993, p.132-133).

Al seguir con el carácter dinámico de la comprensión de la sexualidad del individuo con lesión medular, presento otras experiencias afectivo-sexuales de hombres después de la lesión medular adquirida (BARBOSA, 2003).

La lesión causó una gran diferencia, algo que era muy fácil, por ejemplo, tener sexo con otra persona, ya no tiene la misma facilidad. La vida sexual del hombre discapacitado no es como muchos afirman, no tiene nada que ver [...]. [Colaborador 2, 44 años, pintor] (BARBOSA, 2003, p.115).

[...] yo pensé que ya no era hombre, ya no quería vivir, ¿̨me entiendes? Después empecé a reaccionar y empecé a poner mi vida en marcha, es distinto... al inicio pensé que ya no era hombre, ¿̇me entiendes? No quería sobrevivir, mi mente estaba perfecta, pero yo pensaba tonterías. Si ya no iba a ser hombre, ¿para qué vivir? Si ya no iba a ser hombre. [Colaborador 10, 44 años, vendedor de libros] (BARBOSA, 2003, p.115).

En la trayectoria de los relatos de estos hombres acerca de sus experiencias afectivo-sexuales antes de las secuelas de la lesión medular en relación a aquellas de después de la lesión - momento de desesperación y desesperanza frente a la (im)posibilidad de regresar a un comportamiento sexual sin compromiso y enfocado en la sexualidad con órganos genitales - Giddens (1993) explica que el pene personifica el mantenimiento del poder fálico, precisamente como lo expresa el Colaborador 10: "Yo pensé que ya no era hombre, ya no quería vivir, ¿me entiendes?” Darse cuenta de que ya no posee su poder fálico afecta tanto el centro de su virilidad que le quita el sentido de la vida. 
Dolorosa experiencia. Pero el tiempo, como aliado, le permite volver a simbolizar su mundo-vida de lesionado medular. En las palabras de Le Breton (2011, p.144), "A partir de su propio camino, cada hombre simboliza con su estilo propio el polvo de las situaciones enfrentadas." Y, en este proceso frente a la limitación de las secuelas de la lesión medular, la vida empieza a latir y, poco a poco, el individuo empieza a reaccionar. Como también lo expresa el Colaborador 10: "Al inicio pensé que ya nadie me miraría, después empecé a reaccionar y a poner mi vida en marcha, y ahora mi vida es otra."

A partir de este (in)soportable sufrimiento, él experimenta el latido de la vida en su movimiento y se encuentra perplejo al expresar que, en realidad, la vida no es lo que él creía antes de la lesión, y poco a poco se permite ver la posibilidad de reconstruir sus proyectos de vida.

Superar esta fase exige atribuir otros significados a la vida para permitir la construcción de nuevas representaciones - las bases de creencias, mitos, valores y estilos de vida, como lo describe el colaborador de Barbosa (2003, p.191):

[...] entonces hoy [...] creo que hoy disfruto más de la relación sexual que antes, porque si estoy con mi novia... Hay toques, hay caricias, ¿verdad? Entonces es más placentero, ¿̨no? No es simplemente penetración, eyaculación y listo, cada quien voltea hacia un lado y se acabó, ¡espérame! Tiene ese lado de acariciarnos, de conocernos más... vivir la relación, ¿¿no? Vivir la relación sexual de la forma como lo hago hoy es mucho más placentero que antes de que sufriera el trauma. [Colaborador 8, 29 ańos, psicólogo]

Este proceso es largo e involucra la disponibilidad de la pareja de reconstruir sus expectativas en relación al proyecto familiar y de amistades, y principalmente del equipo responsable del proceso de rehabilitación, que debe estar capacitado para aclarar dudas y curiosidades acerca de la potencia y del desempeño sexual. Especialmente, dominar el encarcelamiento al ethos de patriarcado que sostiene este modelo de virilidad, en el sentido de estimular en este hombre el deseo de reconstruir el espectro erótico de su cuerpo, buscando descubrirlo como un horizonte de fascinantes escenarios eróticos.

Descubrir estos escenarios exige que el individuo se hunda en la desesperación, en la angustia, en la depresión y en el dolor, entre otros sentimientos, para vivir el proceso catártico. Reflexionar acerca de los recuerdos de odio, de resentimiento y de victimización para permitir que nazca una postura flexible de determinación y empiece la reelaboración de nuevos proyectos.

La postura flexible del equipo de rehabilitación en armonía con la del discapacitado, con base en los descubrimientos científicos y en las nuevas tecnologías de accesibilidad, apoyan la apertura de horizontes para que el discapacitado empiece esta nueva planeación. 
El acceso a la información aumenta la perspectiva de todos los seres humanos independientemente de la condición física

Sonidos, susurros, timbres de voz, olores, toques en el cabello y masajes en el cuerpo ocupan un lugar especial en el camino de la intimidad erótica de la persona ciega, por ejemplo. Los discapacitados en silla de ruedas, al restablecer los sentidos de virilidad, son capaces de recriar y reinventar el dominio del arte erótico sobre ruedas, estimulando la imaginación de personas con todas sus capacidades indemnes

La tecnología de las prótesis de última generación ha excedido los límites no solamente en el atletismo, también en la creación de camas y de sillas adecuadas que favorecen la creatividad de la intimidad erótica entre las parejas, sin importar la orientación sexual. El acceso de los individuos en silla de ruedas a estos productos reactiva sus deseos para reinventar la vida después de la lesión medular.

Los sex shops han aumentado su interés en el prometedor mercado de consumo que este nicho del arte erótico sobre ruedas constituye, lo que está en armonía con la propuesta de Medeiros e Diniz (2004, p.108), cuando afirman que:

[...] la discapacidad no debe ser vista como un problema individual, sino como una cuestión altamente social, al transferir la responsabilidad por las desventajas de los discapacitados con relación a sus limitaciones corporales a la incapacidad de la sociedad de prever y adaptarse a la diversidad.

Desde esta perspectiva, los discapacitados rebasan también los límites de los diagnósticos médicos ofrecidos acerca de la posibilidad que tiene una mujer en silla de ruedas de generar una vida, por ejemplo. Según el relato de una mujer en silla de ruedas que buscó información/orientación para poder tener un hijo, el profesional, que no conoce el mundo-vida de los discapacitados, declaró: "Es imposible, tu condición de discapacitada te impide de realizar tu sueño de generar una vida ${ }^{2 "}$. Sin embargo, llena de dudas, pero inundada por el deseo, la discapacitada $\mathrm{X}$ decidió seguir su deseo y, de hecho, se embarazó pocos meses después.

Esta realidad nos enseña que es necesario expandir la reflexión acerca del concepto de discapacidad entre los profesionales y familiares y entre los mismos individuos que experimentan la discapacidad, para que quiten de sí mismos el encarcelamiento a las limitaciones e imperfecciones y exijan de las políticas

2 Nota de relato de una profesional en silla de ruedas durante el III Seminario La sexualidad en la vida de la persona con discapacidad, promovido por la XI Feria Internacional de Tecnología en Rehabilitación, Inclusión y Accesibilidad (REATECH), realizada en el Centro de Exposiciones Imigrante - São Paulo, SP, abril/2012. 
públicas la creación de condiciones que les permitan transitar por la sociedad como sujetos de sus elecciones, de sus decisiones y de sus deseos de ir y venir, independientemente de estas limitaciones (BRUNS, 2014).

Utilizo la definición de lesión y deficiencia de Upias traído por Medeiros e Diniz (2004) para hacer viable este propósito.

'Lesión: ausencia parcial o total de un miembro, órgano o existencia de un mecanismo corporal defectuoso.'

'Discapacidad: desventaja o restricción de actividad provocada por la organización social contemporánea que considera poco o nada aquellos que poseen lesiones físicas y los excluye de las principales actividades de la vida social.'

Es importante señalar que la dificultad de locomoción no es solamente el reflejo de la condición de los discapacitados y de la población longeva; es el resultado de la mala calidad de las vías peatonales y de la inadecuación del sistema de transporte colectivo, que no ofrece a este segmento de la población la autonomía a que tienen derecho. Se entiende la autonomía como la capacidad de promover la crecente capacidad del individuo de orientar su propia vida de forma positiva para sí mismo y para el colectivo (AMATUZZI, 2009).

Medeiros e Diniz (2004) señalan el regreso a la terminología correcta empleada al discutir la discapacidad. Estos autores afirman que hace mucho tiempo se evitaba el uso del término discapacitado para referirse a las personas que experimentaron la discapacidad, por creerse que era un término estigmatizador.

Desde esta perspectiva, se utilizó persona portadora de necesidades especiales o, en estos últimos tiempos, persona con discapacidad; todos tratan de resaltar la importancia de la persona cuando se refieren a la discapacidad. Aquellos que prefieren el reconocimiento de la identidad en la discapacidad utilizan simplemente el término discapacitado, siguiendo principios similares a los que llevan a la preferencia por el término "afrodescendiente para referirse a las personas de color negro o moreno”. (MEDEIROS; DINIZ, 2004, p.107).

Enfatiza los autores que:

La discapacidad no debe ser vista como un problema individual, sino como una cuestión altamente social, al transferir la responsabilidad por las desventajas de los discapacitados con relación a sus limitaciones corporales a la incapacidad de la sociedad de prever y adaptarse a la diversidad. (MEDEIROS; DINIZ, 2004, p.108). 
Los argumentos de los autores reafirman la necesidad que tiene nuestra sociedad de extender sus políticas públicas para informar los individuos acerca de sus derechos educativos, sociales, políticos y sexuales que, en mi opinión, es uno de los caminos hacia la disminución de las dificultades que los individuos discapacitados o no discapacitados enfrentan al experimentar el amor erótico.

Igualmente importante es la extensión de esta visión en el ámbito familiar, educativo y de los medios. Estos ámbitos han pospuesto la oportunidad de asumir una decisión sin el sentimiento de lástima hacia el discapacitado, que lo destruye y aleja de sus derechos a la autonomía para actuar como individuo consciente de su lugar político en la sociedad.

Las escuelas, por ejemplo, al poner en sus currículos desde la Escuela Primaria el aprendizaje del alfabeto Braille y de la Lengua de Seńas, extenderían la calidad de la comunicación entre discapacitados y no discapacitados sin importar el género, la edad y la clase social.

Estas acciones, que ya son practicadas en algunas familias e instituciones escolares, intensifican la desconstrucción de prejuicios entre los considerados normales o anormales, además del concepto de capacitado y discapacitado.

Los medios de comunicación pierden excelentes oportunidades de establecer un dialogo con la escuela y con la población acerca de las dificultades que todos tenemos de dialogar sobre sexo y sexualidad, diversidades afectivo-sexuales, género y, sin dudas, la expresión del amor erótico. Vivimos un momento propicio para iniciar un dialogo con adolescentes y adultos jóvenes con o sin discapacidades acerca de la homofobia, del embarazo en la adolescencia, del bullying en la escuela y en la familia, de la sexualidad de discapacitados y de la experiencia del amor erótico, entre otros aspectos de vida provocadores que afectan la experiencia placentera del ágape que se manifiesta en la amistad, en la solidaridad y en el altruismo - calidades tan valoradas por el individuo contemporáneo.

Es necesario invertir en políticas públicas para mover el paradigma que considera la discapacidad como fenómeno individual al paradigma de las diversidades educativas, sociales, políticas y sexuales; extender las informaciones en el ámbito familiar, educativo y de los medios para crear nuevas estructuras de la experiencia del amor erótico por individuos con o sin alguna discapacidad. 


\section{REFERENCIAS}

AMATUZZI, M. M. Psicologia fenomenológica: uma aproximação teórica humanista. Estudos de Psicologia, Campina, v.26, n.1, p.93-100, 2009.

BATAILLE, G. O erotismo. São Paulo: Arx, 2004.

BARBOSA, V. R. C. A vivência da sexualidade de homens com lesão medular adquirida. 2003. 215f. Disertation (Maestría en Psicología) - Facultad de Filosofía, Ciencias y Letras, Universidad de São Paulo, São Paulo, 2003. Disponible en: <http://www.teses.usp.br/teses/ disponiveis/59/59137/tde-03062009-142233/pt-br.php >. Aceso en: 12 nov. 2015.

BRUM, E. A dor dos filhos. Revista Época, 2012. Disponible en:

<http://revistaepoca.globo.com/Sociedade/eliane-brum/noticia/2012/11/dor-dos-filhos. html>. Aceso en: 12 nov. 2015.

BRUNS, M. A. T. Necesidades especiales y sexualidad: desafios de la inclusión. In: GIROTO, C. R. M. et al.(Org.). Servicios de apoyo en Educación Especial: una mirada desde diferentes realidades. Alcalá de Henares: Universidad de Alcalá, 2014. p.117-190.

BRUNS, M. A. T. Psicoterapeutas iniciantes: os desafios das diversidades afetivo-sexuais. Arquivos Brasileiros de Psicologia, Rio de Janeiro, v.63, n.1, p 64-74, 2011. Disponíble en: <http://seer.psicologia.ufrj.br/index.php/abp/issue/view/24>. Aceso en: 13 jul. 2015.

DALGALARRONDO, P. Psicopatologia e semiologia dos transtornos mentais. Rio Grande do Sul: ARTMED, 2008.

DEL PRIORI, M. História do amor no Brasil. 2.ed. São Paulo: Contexto, 2006. Disponible en:

<http://api.ning.com/files/YvQwzif2nPn84fB7eN-CAmrql1sFvrqy4WEzuE1 Gj4vZJwrEClX915JM1HPdky7v4jy3qw5JZFynkMC3I3tZ0e0Uu8QoZGB1/ MaryDelPrioreHistriadoAmornoBrasil.pdf>. Aceso en: 12 nov. 2015.

DICHTCHEKENIAN, N. Vida e morte em Freud: uma leitura fenomenológica. In: DICHTCHEKENIAN, M. F. S. F. B. (Org.). Vida e morte: ensaios fenomenológicos. São Paulo: Cia. Ltda, 1988. p.99-110.

LE BRETON, D. Antropologia do corpo e modernidade e modernidade. Rio de Janeiro: Vozes, 2011.

GIDDENS, A. A transformaçáo da intimidade: sexualidade, amor e erotismo nas sociedades modernas. São Paulo: Ed. da UNESP, 1993.

GRASSI, M. V. C. Psicopatologia e disfunção erétil. São Paulo: Escuta, 2004.

MARREGA, M. F.; BRUNS, M. A. T. Super-homem e a mudança da história: um estudo sobre os papéis de gênero. In: CUNHA, M. V.; PASIAN, S. R.; ROMANELLI, G. (Org.). Pesquisas em psicologia: múltiplas abordagens. São Paulo: Vetor, 2009. p.83-86.

MEDEIROS, M.; DINIZ, D. Envelhecimento e deficiência. In: CAMARANO, A. A. (Org.). Muito além dos 60: os novos idosos brasileiros. Rio de Janeiro: IPEA, 2004. p.107120. 
PEREIRA, E. C. O eclipse do pai: a aurora de um novo homem. In: GRASSI, M. V. C. Psicopatologia e disfunçáo Erétil. São Paulo: Escuta, 2004. p.12-13.

NÁSIO, J. D. O livro da dor e do amor. Rio de Janeiro: Zahar, 1997.

PAZ, O. A dupla chama: amor e erotismo. São Paulo: Siciliano, 2001.

SANTOS, R. B. Homens com câncer de próstata: um estudo da sexualidade à luz da perspectiva heideggeriana. 2006. 243f. Disertation (Maestría en Psicología) - Facultad de Filosofía, Ciencias y Letras, Universidad de São Paulo, Ribeirão Preto, 2006. Disponible en: <http://www.teses.usp.br/teses/disponiveis/59/59137/tde-21032007-143657/pt-br.php>. Aceso en: 12 nov. 2015. 


\section{Resumen}

\section{Dificultades del amor erótico en los lazos de inclusión}

El erotismo, una creación cultural de cada sociedad, se dio en el proceso de evolución de las especies a través del dominio del instinto sexual reproductor por el hombre transformándolo en una representación mediada en el y por el conjunto de censuras, prácticas, rituales, mitos y tabúes, lo que nos separa de los demás animales. Es experimentado por individuos considerados "normales" y por individuos discapacitados de distintas etnias, culturas, edades y clases sociales. Intento propiciar una reflexión acerca del ethos del patriarcado presente en las dificultades encontradas por los individuos al experimentar el amor erótico. Creo que es importante invertir en políticas públicas para cambiar del paradigma que considera la discapacidad como fenómeno individual al paradigma de las diversidades educativas, sociales, políticas y sexuales; expandir la información en el ámbito familiar, educativo y de los medios, para crear nuevas estructuras de experiencia del amor erótico.

Palabras clave: Erotismo. Inclusión. Patriarcado. Transgresión.

\section{Abstract \\ INCLUSIÓN DIFFICULTIES OF EROTIC LOVE IN THE INCLUSION TIES}

Eroticism, a cultural creation of each society, derives from the evolution of the species through man's domination of the reproductive sexual instinct transforming it into a representation mediated in and by the series of interdicts, practices, rituals, myths and taboos in order to make us different from the other animals. Eroticism is experienced by both those considered "normal" subjects and those considered disabled subjects of every ethnic, cultural and age group and social class. I intend to promote a reflection of the patriarchal culture which permeates the difficulties these subjects face in their experience of erotic love. I believe public policies should shift from the paradigm which focuses the deficiency as an individual phenomenon to the paradigm underlying educational, social, political and sexual diversities and increase the scope of information provided to the family, educational and media spheres so as to develop new tessiture of subjects' experience of erotic love.

Keywords: Eroticism. Inclusion. Patriarchal. Transgression. 